\title{
Income and Calorie Intake among Farming Households in Rural Nigeria: Results of Parametric and Nonparametric Analysis
}

\author{
Raphael Olanrewaju Babatunde (Corresponding author) \\ Department of Agricultural Economics and Farm Management, University of Ilorin \\ P.M.B. 1515 Ilorin, Kwara State, Nigeria \\ Tel: 234-803-288-9769Ｅ-mail: ralphag20@yahoo.com \\ Adedeji Olusayo Adejobi \\ Department of Agricultural Economics, Obafemi Awolowo University, Ile-Ife \\ Osun State, Nigeria \\ Tel: 234-807-640-6331Ｅ-mail: dadejobi@oauife.edu.ng \\ Segun Bamidele Fakayode \\ Department of Agricultural Economics and Farm Management, University of Ilorin \\ P.M.B. 1515 Ilorin, Kwara State, Nigeria \\ Tel: 234-806-023-6283 E-mail: segun_fakayode@yahoo.com
}

\begin{abstract}
There has been an intense debate in the last two decades on the nature of the relationship between income and calorie intake. This paper relooks at the relationship using parametric and nonparametric techniques. The paper employed a survey data set collected from farm households in rural Nigeria. Our analysis indicates that average per capita daily calorie intake in the study area is 2428 kilocalories, which is below the recommended intake level. We find that income has a significant positive relationship with calorie intake. Nonetheless, the calorie-income elasticity is estimated as 0.181 , suggesting that calorie intake does not increase substantially with increases in income. The results also reveal a positive and significant relationship between farm size and calorie intake. A combination of policy strategies, including income growth, agricultural development and targeted food programmes could reduce the problems of inadequate calorie consumption among poor households.
\end{abstract}

Keywords: Calorie intake, Farm households, Nonparametric estimation, Parametric estimation, Per capita income

\section{Introduction}

Inadequate nutrition is perhaps the most important problem facing the poor people in the World today. In spite of the progress made in improving nutrient availability in the last decade, a large proportion of poor households in developing countries still have inadequate access to sufficient food (Abdulai and Aubert, 2004). Although per capita daily calorie intake in developing countries has increased substantially in the last decade, the number of undernourished people is still around 923 Million and the recent food price increases has also triggered an increase in hunger Worldwide (FAO, 2008). Calorie intake has been found to have a strong linkage with both human health and productivity. The human body needs dietary calorie energy to maintain normal body metabolic function and engage in activity related to good health and hygiene. In addition, calorie intake is the main determinant of under nutrition and malnutrition among the people. It is needed for growth and assimilation of micronutrients among children. Inadequate supply of calorie lowers productivity, hinders learning and increases the risk of diseases (Aromolaran, 2004).

The importance of calorie intake coupled with the concern about undernourishment in developing countries has led to increasing number of studies on the determinants of calorie intake. More prominent in the empirical studies is the relationship between income and calorie intake (Abdulai and Aubert, 2004). There has been an intense debate, in the last two decades, on the exact nature of the relationship between income and calorie intake (Gibson and Rozelle, 2000). From this debate emerged two groups of empirical literatures. The first group is of 
the opinion that the level of per capita calorie intake has a strong positive but non-linear relationship with income, and that increases in income will lead to substantial increase in calorie intake (Grimard, 1996; Subramanian and Deaton, 1996). On the contrary, the second group of literatures suggests that the linkage between income and calorie intake is weak and therefore, increases in income will not result in substantial improvement in calorie intake (Behrman and Deolalikar, 1987; Boius and Haddad, 1992).

This divergent opinions call for more empirical research to analyze the income-calorie relationship in specific setting and provide plausible results that could be use to generate appropriate policy responses. In this paper, we analyze income-calorie relationship among farming households using a recent survey data set from rural areas of Nigeria. Most empirical studies that have analyzed the income-calorie relationship in Nigeria rely only on parametric approach (e.g. Aromolaran, 2004; Agbola et. al., 2004). Yet, parametric estimations are not only prone to error - due to biased estimation, (Note 1) they are also based on an explicit assumption of a linear relationship between income and calorie intake. In recent times this assumption has been challenged and there is a major concern about the issue of potential non-linearity of the income-calorie relationship. For instance, while it has been suggested that calorie intake is likely to respond positively to income increases among the poor, the elasticity could decline, possibly to zero or even negative as income increases. Related to this, also is the assertion that income-calorie curve can be elbow-shaped in very poor households. According to this argument, per capita calorie intake may first decline with increasing income, as households concerned with the monotony of their diets, devote a good deal of extra income to buying expensive calories. However, as income increases, per capita calorie intake rises, and then finally declines with further increase in income (Abdulai and Aubert, 2004).

The consequence of this is that the popular parametric estimations may not provide sufficient tools to explain the nature of the income-calorie relationship and a combination of approaches would be needed to adequately examine the relationship. This paper therefore contributes to the empirical literatures by using both parametric and nonparametric approaches to analyze the nature of the income-calorie relationship in Nigeria. In addition, we are not aware of any recent study that has used this combination of analytical techniques to analyze the income-calorie relationship in Nigeria. Nonparametric techniques represent a set of tools for analyzing unknown regression relationship. Apart from allowing data to search appropriate non-linear forms of the relationship, they are also consistent under less restrictive assumptions than those underlying the parametric techniques (Abdulai and Aubert, 2004).

The paper is organized as follows. Section 2 discusses the data and sample characteristics. Section 3 presents and discusses the results of the descriptive, nonparametric and parametric analyses. Section 4 concludes the paper with a discussion of the policy implications of the results.

\section{Data and sample characteristics}

\subsection{Data collection procedure}

The data used for this study is obtained from a comprehensive survey of farm households in Kwara State, north-central region of Nigeria. The state has a total population of about 2.4 million people, $70 \%$ of which can be classified as smallholder farmers. The farming system is characterized by low quality land, low population density, and predominantly cereal-based cropping systems. Farm enterprises are generally small in size, so that in spite of own production - most households are net buyers of food, at least seasonally (KWSG, 2006). According to the nationwide living standard measurement survey conducted in 2004, Kwara State is among the six poorest in Nigeria in terms of undernourishment and income poverty. About $83 \%$ of the population of the State classified themselves as being poor (NBS, 2006).

A three-stage random sampling technique was used to select the sample respondents for the analysis. Eight out of the 16 local government areas in Kwara State were randomly selected in the first stage. (Note 2) Then, five villages were randomly chosen from each selected local government area, and finally, six households were sampled in each of the resulting 40 villages, using complete village household lists provided by the local authorities. Thus, a total of 240 households in all were selected. Personal interviews were carried out with the household head, usually in the presence of the spouse or other family member responsible for preparing the family meals. A standardized questionnaire was used that covered information on household expenditure, consumption, farm and off-farm income, socioeconomic characteristics, and various institutional and contextual variables. Farm income covers commodity sales and subsistence production, both valued at local market prices. Respondents were asked to specify in detail all inputs used, outputs obtained, and prices for the different crop and livestock activities over the 12-months period prior to the survey. Non-farm income and other income were 
recorded separately for all household members, also covering a 12-months period, in order to avoid a seasonality bias.

Food consumption data was collected at the household level covering 105 food items. Quantities consumed include food from own production, market purchases, and out-of-home meals and snacks. While also here it would be desirable to have annual data that are free from seasonality effects, it is well known that the accuracy of food consumption data is negatively correlated with the length of the recall period (e.g., Bouis, 1994). Hence, we decided to use a 7-day recall in our survey. The survey was carried out in the lean season, during which household food consumption is often below the annual average. Therefore, the calorie intake data might be somewhat underestimated. (Note 3) Food quantities consumed at the household level were converted to calories using the locally available food composition table (Oguntona and Akinyele, 1995). Resulting calorie values were divided by the number of Adult Equivalent (AE) in a household, in order to obtain the per capita calorie intake. (Notes 4) This value was again divided by the 7-days recall period to obtain per capita daily calorie intake of each household. We define a food secure household as one whose daily calorie intake per AE is greater than or equal the minimum daily calorie requirement for adult men of $2500 \mathrm{kcal}$ (FAO/WHO/UNU, 1985). Households with lower calorie intakes are considered to be undernourished. After cleaning the data, 20 of the questionnaires were found unsuitable for analysis.

\subsection{Sample characteristics}

The average household size in the sample consists of 5 persons. This is in line with the national average in Nigeria reported by NBS (2006). The dependency ratio of 0.54 in the sample is lower than the national average. This is probably due to the low population density of the State. About $10 \%$ of the households are headed by women (Table 1). The average age of husband in the study area is 59 years. The average husband has 6.9 years of schooling while the average wife has 3 years of schooling. The mean farm size of 1.9 ha is comparable to the national average of 2 ha. Average year of farming experience in the study area is 35 years and the average household has productive assets worth 74 thousand naira. The infrastructure variables indicate that many of the farm households do not have access to electricity, tapped water, or a tarred road. Even fewer households have access to formal or informal credit. The mean distance to the nearest market place is 11.7 kilometers.

Table 1 shows that the total annual household income is approximately 30 thousand naira (250 US\$) per AE. This is somewhat lower than the national average in Nigeria, but it appears reasonable for a rural area. The average household income further confirms the level of poverty in the State as discussed earlier. The average per capita daily calorie intake of $2428 \mathrm{kcal}$ in the study area is slightly below the $2500 \mathrm{kcal}$ recommendation, but it is in line with another recent study for rural Nigeria (Aromolaran, 2004). We also observe that farming serves as major occupation for about $60 \%$ of the husbands in the study area. On the other hand, $40 \%$ of the wives are into commodity trading. About $42 \%$ of the household heads are member of cooperatives and close to $90 \%$ have access to some off-farm income.

\section{Empirical analysis and results}

\subsection{Descriptive analysis}

We start the analysis by looking at income and nutrition indicators across different household types. This is done by disaggregating our sample data by income quartiles and estimating calorie intake, prevalence of undernourishment, depth of calorie intake inadequacy, dietary quality as well as dietary diversity, for each income quartile. The results are presented in table 2. It can be shown from table 2 that richer households consume higher calories than poorer households. Consequently, the prevalence of undernourishment and depth of calorie intake inadequacy are lower in richer than in poorer households. Furthermore, dietary quality measured in terms of calorie intake from fruits, vegetables, and animal products is positively correlated with household income. Similarly, dietary diversity - measured as the number of food groups out of 7 , eaten by household over a 7-days period is positively related with income. The results in table 2 show that calorie intake as well as other nutrition indicators is positively related with income. However, given that these results are descriptive in nature, they cannot establish the magnitude of the influence of income on calorie intake. This is done more explicitly in the following sections.

\subsection{Nonparametric estimation}

As mentioned earlier, nonparametric analysis provides useful tools for non-linear modeling and helpful diagnostics. When there is sufficient data, it can also reveal features of the data that are invisible under parametric techniques. An obvious deficiency of the nonparametric approach is that it is restricted to bivariate relationship (Gibson and Rozelle, 2000). Ideally, it would be better to examine the effect of income on calorie 
intake after controlling for households and demographic variables. However, we do not consider this deficiency to be a serious one in our case, since the nonparametric analysis is supplemented with parametric estimations as well. We begin the nonparametric analysis of the data by looking at the kernel density estimator of logarithm of per capita income as well as that of per capita income. (Notes 5) These are shown in figures 1 and 2 below. Figure 1 shows that the shape of kernel density estimator of the logarithm of per capita income followed the popular normal distribution pattern, though slightly skewed to the right. The dispersion of per capita calorie intake has a similar distribution as that of per capita income (Figure 2).

Nonparametric estimation of the relationship between per capita income and per capita calorie intake is shown in figure 3. Irrespective of the bandwidth used, the estimate indicates a positive linear income-calorie relationship. This is in line with the results of Subramanian and Deaton (1996) and Abdulai and Aubert (2004) in rural India and Tanzania respectively. The observed linear relationship is expected in a low-income setting where majority of the households are generally poor. The marginal effect of income increases on calorie intake is analyzed further in the following section. Figure 4 also shows the relationship between logarithm of price of calorie and logarithm of per capita income. With a bandwidth of 0.8 the figure portrays a linear relationship, implying that higher per capita income is associated with higher calorie prices.

\subsection{Parametric estimation}

\subsubsection{Estimation procedures}

The main hypothesis to be tested in this study is that, increase in household income would increase per capita calorie intake among the sampled households. For the purpose of the analysis, we specify a calorie consumption model represented as:

$$
C=\alpha_{0}+\alpha_{1} I+\alpha_{2} P+\alpha_{3} H+\varepsilon
$$

Where $C$ is per capita daily calorie intake (kcal), $I$ is total income per capita in naira, $P$ is the vector of household head individual variables (gender, age, education), $H$ is the vector of household level assets and other variables, and $\varepsilon$ is the random error term. In this model the main parameter of interest is $\alpha_{1}$ - in terms of the sign and magnitude. Based on evidence from empirical literatures, we expect a positive and significant $\alpha_{1}$ (Aromolaran, 2004).

After specifying the model, the next task was to decide on which explanatory variables to include in the model. The justification for the included variables is as follows. According to existing literatures, household size is an important variable in calorie consumption studies. It is believed that lesser calorie might be available to individuals in larger households than in smaller households. The gender, age and education of household head are also important factors in calorie supply and consumption (Behrman and Wolfe, 1984). While age and education might affect income generating and food cultivation ability - especially under the subsistence condition, gender affect access to certain productive resources. Farm size and crop output are important as they might reflect the own-food production ability of the household when other factors are kept constant. Distance to market might affect household access to market-purchased calories - especially during the lean season, when most average households in the study area are net food buyers. Finally, we include per capita annual income of the households, which is the variable of interest in this study. According to Gibson and Rozelle (2000), the orthodox view in development economics has been that increases in income of the poor have beneficial effect on calorie intake.

We start the estimation first by using the Ordinary Least Square (OLS) regression method to estimate equation (1). Several functional forms were tried with the linear function given the best fit. This is probably due to the existence of several zero values for some covariates such as education of the household's head. The results of the OLS estimation are shown in column (1) of table 3. However, given the multi-stage random sampling approach of selecting our respondents, where household's observations are clustered by villages, the OLS method could lead to biased estimates. In other words, there could be potential intra-cluster correlation of the error term which would produce inconsistent variance-covariance matrix (Deaton, 1997). To eliminate this problem, we introduced a cluster correction approach into the OLS estimation. The resulting cluster-corrected estimates and robust standard errors are shown in column (2) of table 3.

Apart from the issue of village clustering mentioned above, estimating equation (1) by OLS could also lead to endogeneity problem arising from reverse causality between calorie intake and income (i.e. income not exogenous as assumed). According to the efficiency wage hypothesis, higher income earning opportunities are open to those who are better nourished (Aromolaran, 2004). (Note 6) In order to avoid this endogeneity bias, we estimate the model again, using an instrumental variable (IV) approach. In the IV estimation, household income 
was instrumented using household assets, access to electricity and credit as instruments. This is similar to approaches that have been used by Gibson and Rozelle (2000) and Ruel et. al. (1999) in different contexts. The results of the IV estimation are displayed in column (3) of table 3, while the first stage regression results are shown in table 4 . We rely on the results of IV estimation for our discussion of the parametric analysis.

\subsubsection{Estimation results}

Column (3) of table 3 shows that income has a positive and significant effect on calorie intake among the households. This is consistent with the nonparametric results of section 3.2. The result is also in agreement with those of other previous studies from Nigeria (Aromolaran, 2004 and Agboola et. al., 2004). Our result indicates that an increase in household annual per capita income by 1000 naira will result in an average per capita calorie intake improvement of 20 kilocalories per day. From the estimated parameter of income variable, we calculate the calorie-income elasticity and found that it is 0.181 , implying that a $10 \%$ increase in income will result in $1.81 \%$ increase in calorie intake. This elasticity is comparable to 0.194 obtained by Aromolaran (2004) from South Western Nigeria. Farm size contributes positively and significantly to calorie intake with a marginal effect of 217 kilocalories per additional hectare.

The results further show that age of household head has a significantly negative effect on calorie intake. This is probably because older people are often less aware of the need for adequate nutrition intake. Moreover, the capacity to access sufficient calories declines with age. It can be shown from column (3) that male-headed households consume more calories than female-headed ones. Though women appear to be more concerned about household nutrition than their men counterparts, they are often disadvantaged in terms of access to some productive resources and social status. Finally, household size has a significant negative impact on calorie intake suggesting that per capita calorie intake decreases in larger households. This might potentially be due to economies of scale in food preparation and consumption: in larger families there is often less food waste than in smaller ones, so that lower average calorie intake does not inevitably mean lower calorie intake.

\section{Conclusion}

This paper investigates the relationship between income and calorie intake in rural areas of Nigeria, using both nonparametric and parametric approaches. We utilized primary data collected in the summer of 2006 from 220 farm households randomly selected across 40 villages in Kwara State. Descriptive analysis was used to describe the relationship between income and calorie intake, as well as other nutrition indicators. Nonparametric estimation was used to examine the income-calorie relationship, which was later tested formally using parametric estimations.

The major findings of the study are as follows. First, we find that the average per capita daily calorie intake in the study area is about 2428 kilocalories. This suggests that the area is calorie-deficient generally and more attention is needed to bring calorie consumption to the recommended level of 2500 kilocalories per capita per day. Disaggregating calorie intake by income quartiles indicates that the calorie consumption of the poor households is comparatively much less than those of rich households. Therefore, we suggest that policy interventions should also include measures to boost the income of the very poor households so that they can increase their calorie intake.

Second, both nonparametric and parametric estimations results show a positive relationship between income and calorie intake among the sample households. This result confirms our stated hypothesis of a positive income-calorie relationship in a low-income population such as Nigeria. The estimated calorie-income elasticity is 0.181 suggesting that a $100 \%$ increase in income will result in about $18 \%$ increase in calorie intake. The implication of the low calorie-income elasticity is that, among poor households in low income countries, increase in income will not lead to a very substantial increase in calorie intake.

Third, our analysis reveals that farm size has a positive and significant effect on calorie intake, suggesting that increases in farm size cultivated will lead to increase in calorie intake. We suggest that farming households in the area should take advantage of the calorie intake effect by increasing their farm land holding, especially through group farming and mechanization.

\section{References}

Abdulai, A. \& Aubert, D. (2004). Nonparametric and Parametric Analysis of Calorie Consumption in Tanzania. Food Policy, 29, 113-129

Agboola, P.O; Ikpi, A.E \& Kormawa, P.M. (2004). Factors Influencing Food Insecurity among Rural Farming Households in Africa: Results of Analysis from Nigeria. Internet Discussion Paper, November, 2004. 
Aromolaran, A.B. (2004). Household Income, Women's Income Share and Food Calorie Intake in South Western Nigeria. Food Policy, 29, 507-530.

Behrman, J.R. \& Deolalikar, A.B. (1987). Will Developing Country Nutrition Improve with Income? A Case Study of Rural India. Journal of Political Economy, 95, 492-507.

Behrman, J.R. \& Wolfe, B.L. (1984). More Evidence on Nutrition Demand: Income Seems Overrated and Women's Schooling Underemphasized. Journal of Development Economics, 14, 105-128.

Bouis, H.E. (1994). The Effect of Income on Demand for Food in Poor Countries: Are our Food Consumption Databases Giving us Reliable Estimates? Journal of Development Economics, 44, 199-226.

Bouis, H.E. \& Haddad, L.J. (1992). Are Estimates of Calorie-Income Elasticities Too High? A Recalibration of the Plausible Range. Journal of Development Economics, 39, 333-364.

Deaton, A. (1997). The Analysis of Household Surveys. Johns Hopkins University Press, Baltimore, MD. FAO. (2008). The State of Food Insecurity in the World 2008. Food and Agriculture Organization, Rome.

FAO/WHO/UNU. (1985). Protein and Energy Requirements, Food and Agriculture Organization, World Health Organization, United Nations University, Rome.

Gibson, J. \& Rozelle, S. (2000). How Elastic is Calorie Demand? Parametric, Nonparametric, and Semiparametric Results for Urban Papua New Guinea. Working Paper No. 22, Department of Agricultural and Resource Economics, University of California, Davis.

Grimard, F. (1996). Does the Poor's Consumption of Calorie Respond to Changes in Income? Evidence from Pakistan. The Pakistan Development Review, 35, 257-283.

KWSG. (2006). Kwara State Government of Nigeria, Planning Studies in Kwara State. Ministry of Land and Regional Planning, Ilorin.

NBS. (2006). National Bureau of Statistics, Abuja, Socio-economic Survey of Nigeria.

Oguntona, E.B. \& Akinyele, I.O. (1995). Nutrient Composition of Commonly Eaten Foods in Nigeria:Raw, Processed and Prepared. Food Basket Foundation Series, Ibadan.

Ruel, M.T., Levin, C.E., Armar-Klemesu, M., D. Maxwell, \& Morris, S.S. (1999). Good Care Practices can Mitigate the Negative Effects of Poverty and Low Maternal Schooling on Children's Nutritional Status: Evidence from Accra. World Development, 27, 1993-2009.

Subramanian, S. \& Deaton, A. (1996). The Demand for Food and Calories. Journal of Political Economy, 104, 133-162.

\section{Notes}

Note 1. Sources of bias in parametric estimations include simultaneity bias due to endogeneity of household income and random measurement error bias.

Note 2. Local government area is the smallest administrative unit in Nigeria, usually made up of several wards. A ward consists of several villages that often composed of people of related ethnicity and culture.

Note 3. We do not consider this a major problem here, since our primary objective is to determine the nature of the relationship between income and calorie intake.

Note 4. This procedure implicitly assumes that food is distributed equally within each household. More detailed analysis of intra-household distribution is not possible with our data.

Note 5. We employed the kernel density estimator here because it is easy to use and it permits the data to search the best specification.

Note 6. The same explanation might be extended to farm size - that is, better nourished households may be able to cultivate more land, but because of lack of appropriate instruments, farm size was not instrumented. 
Table 1. Summary statistics of socio-economic characteristic of farm households

\begin{tabular}{|c|c|c|}
\hline Variables (unit) & $\begin{array}{c}\text { Mean value/ } \\
\text { dominant indicator }\end{array}$ & $\begin{array}{l}\text { Standard } \\
\text { deviation }\end{array}$ \\
\hline Household size (AE) & 5.08 & 1.305 \\
\hline Dependency ratio (\%) & 0.540 & 0.900 \\
\hline Gender of household head $($ male $=1$, female $=0)$ & 0.895 & 0.306 \\
\hline Age of household head (years) & 59.1 & 6.80 \\
\hline Age of spouse (years) & 45.1 & 6.45 \\
\hline Education of household head (years of schooling) & 6.89 & 3.93 \\
\hline Education of Spouse (years of schooling) & 3.01 & 3.24 \\
\hline Farm size cultivated by household (ha) & 1.90 & 0.58 \\
\hline Farming experience of household head (years) & 35.3 & 10.8 \\
\hline Productive assets of household (naira) & 73761.8 & 53154.0 \\
\hline Access to electricity $\quad($ yes $=1$, no $=0)$ & 0.827 & 0.378 \\
\hline Access to pipe-borne water $($ yes $=1$, no $=0$ ) & 0.650 & 0.478 \\
\hline Access to tarred road (yes $=1$, no $=0$ ) & 0.740 & 0.439 \\
\hline Access to $\operatorname{credit}($ yes $=1$, no $=0)$ & 0.204 & 0.404 \\
\hline Distance to nearest market $(\mathrm{km})$ & 11.7 & 12.89 \\
\hline Total annual income (naira/AE) & 30245.7 & 23416.4 \\
\hline Household calorie intake (kcal/day/AE) & 2427.5 & 704.0 \\
\hline Major occupation of household head & $60 \%$ into farming & - \\
\hline Major occupation of spouse & $40 \%$ into trading & - \\
\hline Membership of cooperatives & $42.3 \%$ are members & - \\
\hline Access to off-farm income & $87.7 \%$ have access & - \\
\hline
\end{tabular}

Source: computed from survey data. $\mathrm{AE}$ is adult equivalent. Sample size $=220$ 
Table 2. Calorie intake according to income quartiles

\begin{tabular}{|c|c|c|c|c|c|}
\hline & \multirow{2}{*}{$\begin{array}{c}\text { All } \\
\text { households }\end{array}$} & \multicolumn{4}{|c|}{ Income quartiles } \\
\hline & & First & Second & Third & Fourth \\
\hline & \multicolumn{5}{|c|}{ Mean (standard deviation) } \\
\hline \multirow[t]{2}{*}{ Total income (naira/AE) } & 30245.7 & 13862.7 & 23877.2 & 36826.9 & 46416.1 \\
\hline & $(23416.4)$ & $(16231.1)$ & $(11271.9)$ & $(27681.3)$ & $(10887.2)$ \\
\hline \multirow[t]{2}{*}{ Calorie intake (kcal/day/AE) } & 2427.5 & 1943.7 & 2386.5 & 2480.3 & 2899.5 \\
\hline & $(704.0)$ & $(494.6)$ & $(759.4)$ & $(654.1)$ & $(513.3)$ \\
\hline Prevalence of undernourishment (\%) & 60.9 & 96.4 & 67.3 & 52.7 & 27.3 \\
\hline Depth of calorie intake deficiency $(\%)^{a}$ & 22.2 & 25.7 & 22.5 & 21.5 & 10.3 \\
\hline \multirow[t]{2}{*}{ Dietary quality $(\mathrm{kcal} / \mathrm{day} / \mathrm{AE})^{\mathrm{b}}$} & 436.9 & 349.9 & 429.6 & 446.4 & 521.9 \\
\hline & $(126.7)$ & $(89.8)$ & $(136.6)$ & $(118.2)$ & $(95.9)$ \\
\hline \multirow[t]{2}{*}{ Dietary diversity (number) ${ }^{\mathrm{c}}$} & 5.30 & 4.10 & 4.96 & 5.67 & 6.45 \\
\hline & $(1.63)$ & $(1.17)$ & $(1.71)$ & $(1.50)$ & $(1.01)$ \\
\hline
\end{tabular}

Source: computed from survey data. Note: Official exchange rate in 2006: 1 US dollar $=120$ naira. AE is adult equivalent.

${ }^{a}$ This refers only to food insecure households.

${ }^{b}$ This is the calorie supply that comes from fruits, vegetables, and animal products.

${ }^{c}$ This is the number of food groups out of seven, eaten by households over a 7-days period. 
Table 3. Determinants of calorie intake

\begin{tabular}{|c|c|c|c|}
\hline \multirow[t]{4}{*}{ Explanatory variables } & \multicolumn{3}{|c|}{ Per capita calorie intake } \\
\hline & (1) & (2) & (3) \\
\hline & $\begin{array}{l}\text { OLS without cluster } \\
\text { correction }\end{array}$ & $\begin{array}{l}\text { OLS with cluster } \\
\text { correction }\end{array}$ & $\begin{array}{l}\text { IV with cluster } \\
\text { correction }\end{array}$ \\
\hline & $\begin{array}{l}\text { Coefficient } \\
\text { (std. error) }\end{array}$ & $\begin{array}{c}\text { Coefficient } \\
\text { (robust std. error) }\end{array}$ & $\begin{array}{c}\text { Coefficient } \\
\text { (robust std. error) }\end{array}$ \\
\hline Constant & $\begin{array}{c}2803.65^{* * * *} \\
(394.27)\end{array}$ & $\begin{array}{c}2803.65^{* * * *} \\
(374.34)\end{array}$ & $\begin{array}{c}2589.67 * * * \\
(403.12)\end{array}$ \\
\hline Household size (AE) & $\begin{array}{c}-131.82 * * * \\
(31.34)\end{array}$ & $\begin{array}{c}-131.82 * * * \\
(37.36)\end{array}$ & $\begin{array}{c}-102.09 * * \\
(42.23)\end{array}$ \\
\hline Gender of household head (dummy) & $\begin{array}{l}215.36^{*} \\
(122.08)\end{array}$ & $\begin{array}{l}215.36^{*} \\
(117.70)\end{array}$ & $\begin{array}{c}312.62 * * * \\
(110.11)\end{array}$ \\
\hline Age of household head (year) & $\begin{array}{c}-13.13 * * \\
(5.18)\end{array}$ & $\begin{array}{c}-13.13 * * * \\
(4.09)\end{array}$ & $\begin{array}{c}-12.95 * * \\
(5.06)\end{array}$ \\
\hline Education of household head (year) & $\begin{array}{c}14.90 \\
(12.06)\end{array}$ & $\begin{array}{c}14.90 \\
(12.91)\end{array}$ & $\begin{array}{l}-12.10 \\
(15.26)\end{array}$ \\
\hline Farm size (ha) & $\begin{array}{c}282.06 * * * \\
(64.23)\end{array}$ & $\begin{array}{c}282.06 * * * \\
(84.04)\end{array}$ & $\begin{array}{l}217.47 * * \\
(99.79)\end{array}$ \\
\hline Crop output (kg/AE) & $\begin{array}{l}0.684 * \\
(0.375)\end{array}$ & $\begin{array}{l}0.684 * \\
(0.396)\end{array}$ & $\begin{array}{l}-0.437 \\
(0.671)\end{array}$ \\
\hline Distance to market $(\mathrm{km})$ & $\begin{array}{c}-7.94 * * \\
(3.39)\end{array}$ & $\begin{array}{l}-7.94 * \\
(3.98)\end{array}$ & $\begin{array}{l}-1.252 \\
(4.89)\end{array}$ \\
\hline Total income (naira/AE) ${ }^{\mathrm{a}}$ & $\begin{array}{l}0.010^{* *} \\
(0.002)\end{array}$ & $\begin{array}{l}0.010^{* *} \\
(0.002)\end{array}$ & $\begin{array}{c}0.019 * * * \\
(0.006)\end{array}$ \\
\hline $\mathrm{R}^{2}$ & 0.503 & 0.503 & 0.415 \\
\hline F-statistic & 26.77 & 38.94 & 24.93 \\
\hline
\end{tabular}

$*, * *, * * *$ indicate statistically significant at the $10 \%, 5 \%$, and $1 \%$ level, respectively. Note: $\mathrm{N}=220 . \quad$ Number of cluster villages $=40$.

${ }^{\text {a }}$ Variable treated as endogenous in the instrumental variable model, and for predictions, access to electricity, access to credit and household assets were used as instruments. 
Table 4. First stage regression of the IV model explaining per capita income

\begin{tabular}{lcc}
\hline & Coefficient & t-value \\
\hline Constant & 8279.61 & 0.74 \\
Household size (AE) & $-2833.44^{* * *}$ & -3.18 \\
Gender of household head (dummy) & $-8577.84^{* *}$ & -2.50 \\
Age of household head (year) & 46.71 & 0.32 \\
Education of household head (year) & $1465.08^{* * *}$ & 4.36 \\
Farm size (ha) & $5110.68^{* * *}$ & 2.85 \\
Crop output (kg/AE) & $75.35^{* * *}$ & 8.13 \\
Distance to market (km) & $-389.86^{* * *}$ & -4.19 \\
Electricity (dummy) & $6549.89^{* *}$ & 2.35 \\
Credit (dummy) & $-3929.36^{*}$ & -1.78 \\
Productive assets (thsd. Naira) & $80.53^{* * *}$ & 3.78 \\
$\mathrm{R}^{2}$ & 0.638 & \\
F-statistic & 36.98 & \\
\hline
\end{tabular}

Notes: $\mathrm{N}=220 . \quad *, * *, * * *$ indicate statistically significant at the $10 \%, 5 \%$, and $1 \%$ level, respectively.

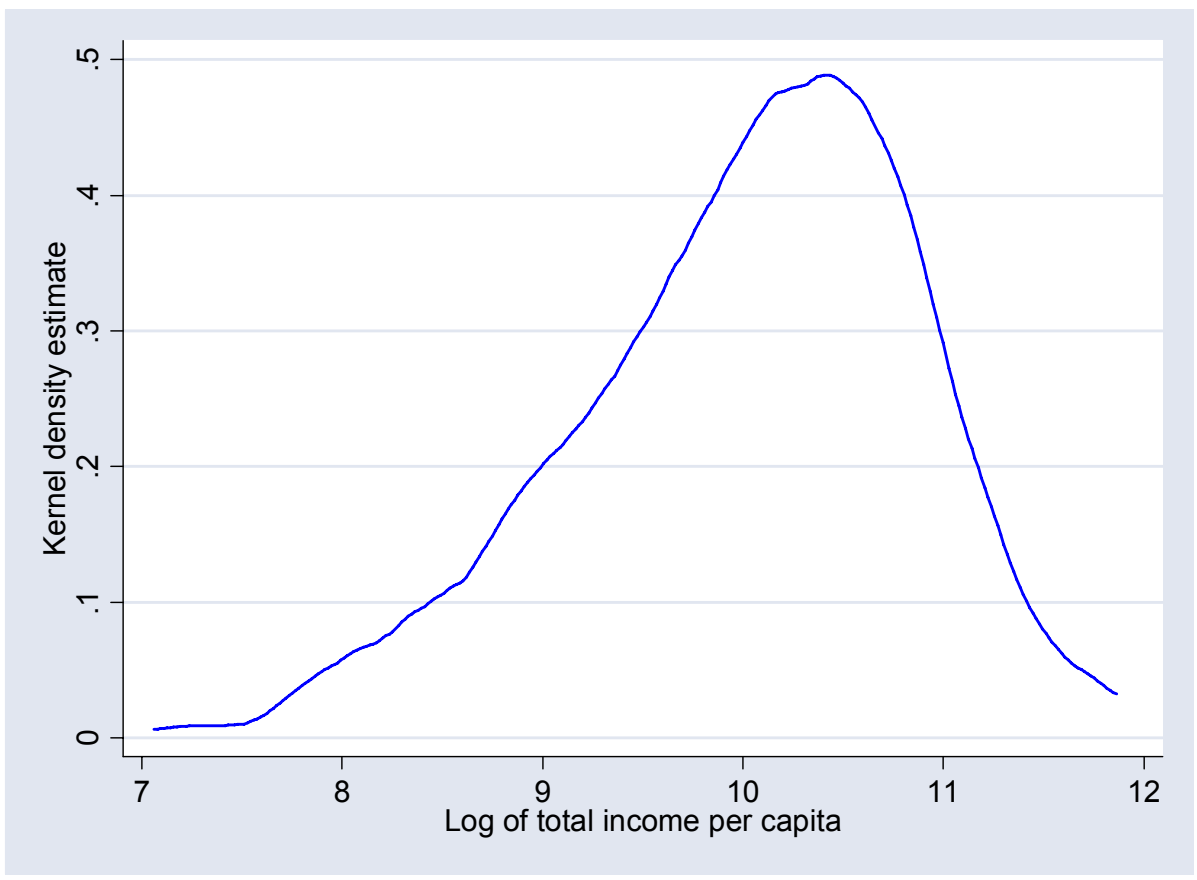

Figure 1. Estimated kernel density of log of total income per capita 


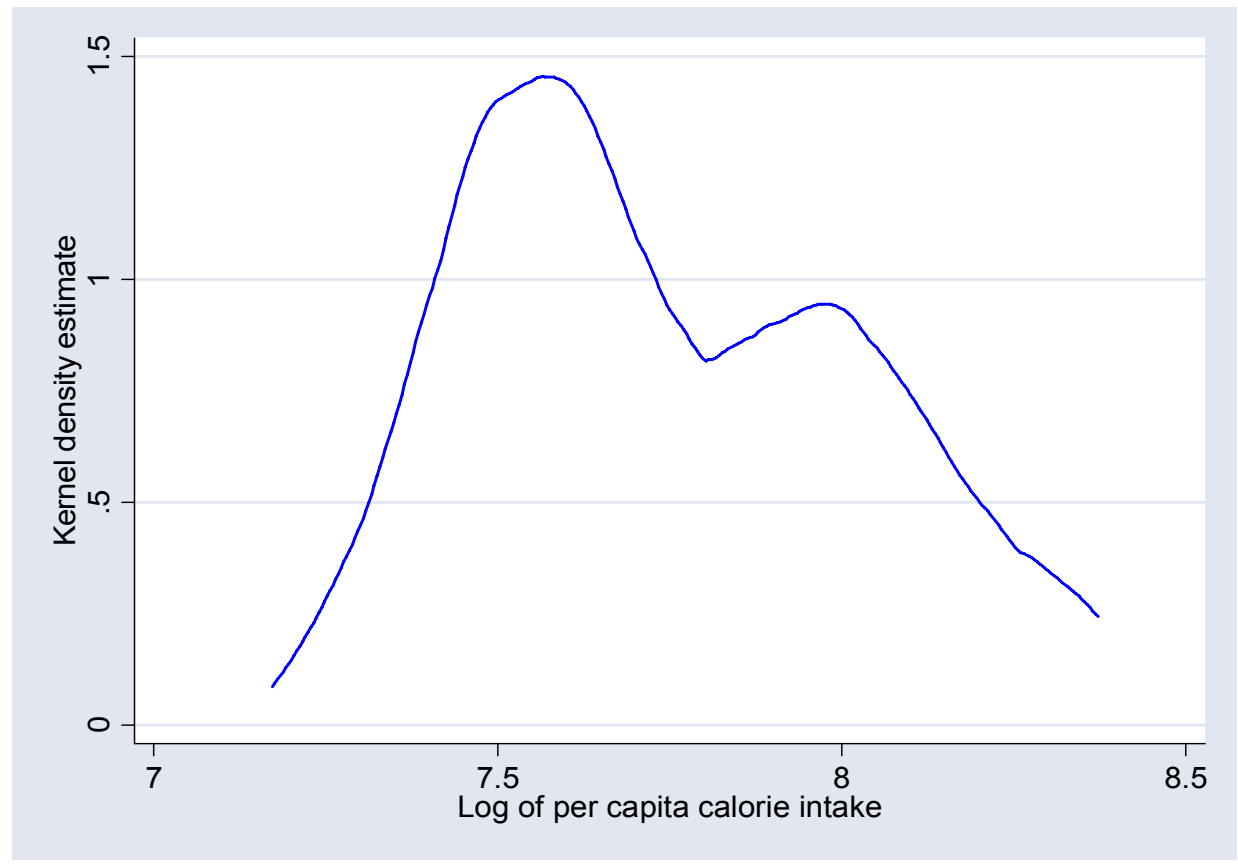

Figure 2. Estimated kernel density of log of per capita calorie intake

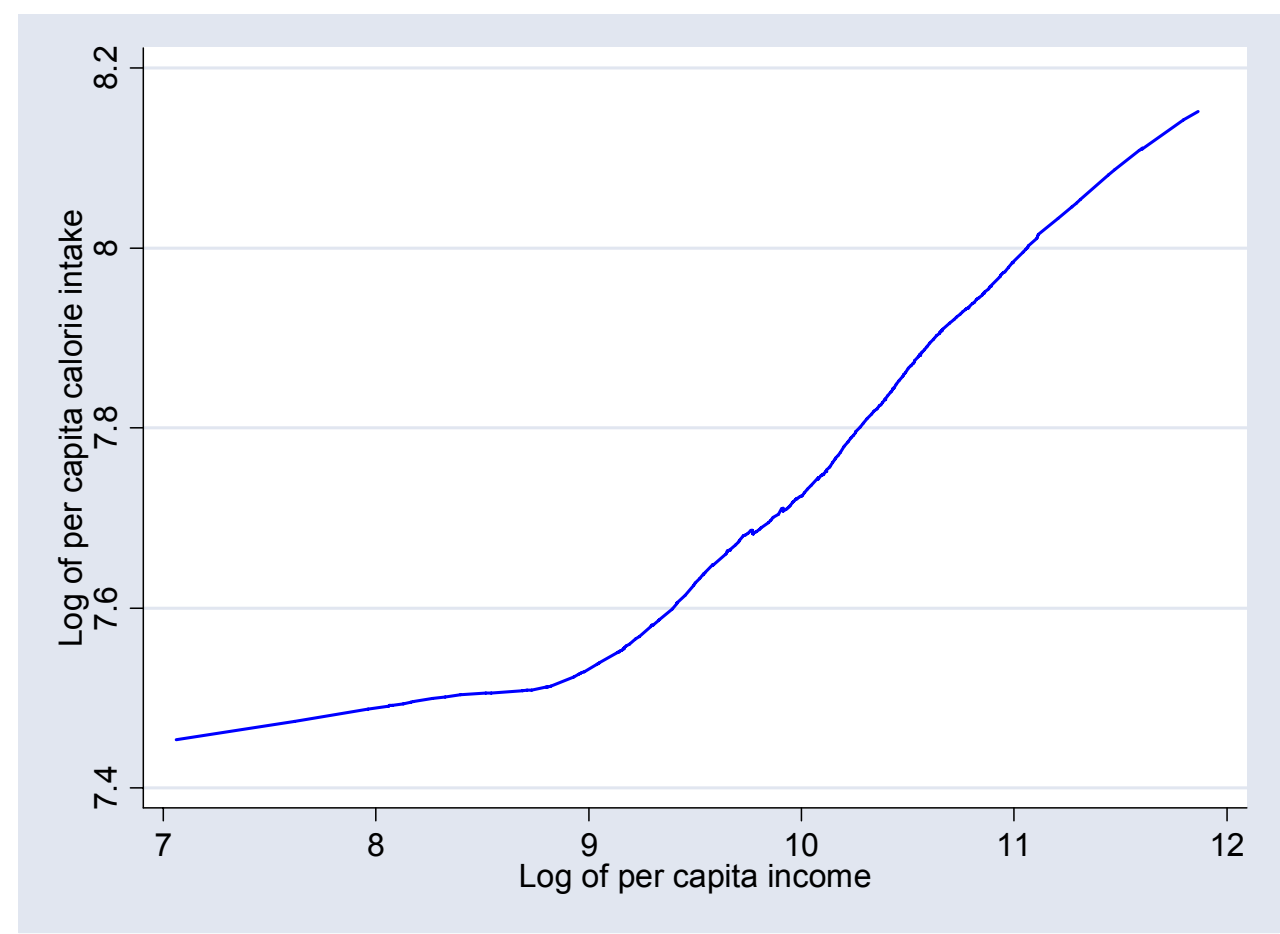

Figure 3. Nonparametric estimate of log of calorie intake and log of per capita income 


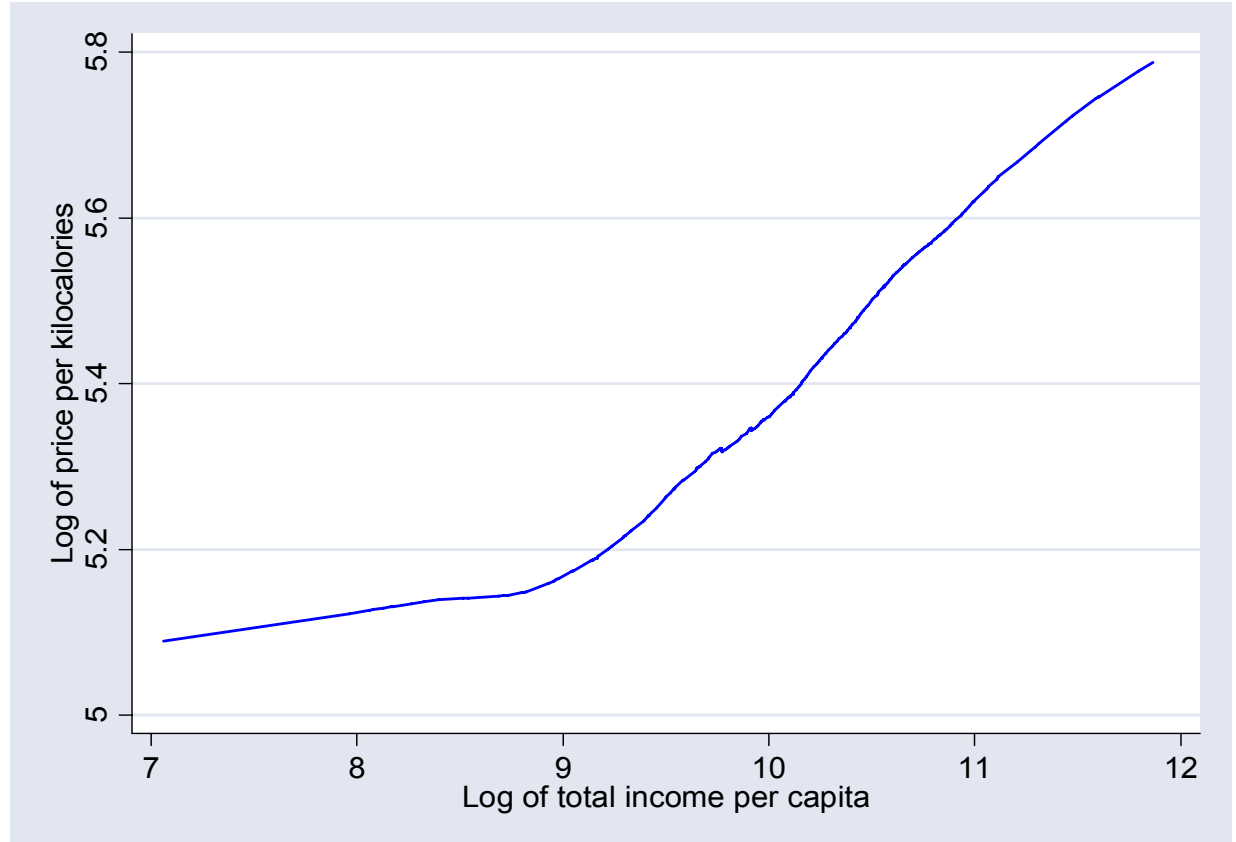

Figure 4. Nonparametric estimate of log of price per kilocalories and log of per capita income 